\title{
Audio-Visual Aids to Teaching Some Reviews of Recent Videotapes
}

Friends and Neighbours (UK, 1985, 32 mins)

This tape is concerned with the rights of the mentally handicapped and the process of normalisation, its main purpose being to promote better understanding of the problems by the general public through the example of the Gloucester style of service. It is a competent production with a well-written script, good editing and an excellent commentary. It gives a useful indication of the contributions from the voluntary sector and it contains a valuable discussion about sex-related problems.

There is a liberal helping of 'talking heads'-the camera work might have been more mobile-and it does tend to lack form (the end sequence about children seems almost an afterthought). The impression is given that other agencies deal with super-added mental illness, offenders, etc., and the blurring of professional images (e.g. of nurses) seems to put them metaphorically almost out of clinical focus!

This is a sincere production, however, that carries conviction and it can be thoroughly recommended for general audiences to open up discussion.

Production: Gloucester Health Authority. Medical Advisers: Drs Jack Bavin and David Wilson. Format: VHS, $£ 120$ plus VAT (two weeks' free preview). Distributors: Video Library, Medical Centre, Torbay Hospital, Torquay TQ2 7AA.

Convenor, Audio-Visual Group

T. L. Pilkington

Detention at the Government's Pleasure (TBR) (Netherlands, 1985, colour, 85 mins)

This tape is an investigative, journalistic view of the treatment of certain recidivists in conditions of security in Holland. It illustrates some of the difficulties of treating these problem people. TBR is roughly the equivalent of Sections 37/41 of the Mental Health Act 1983

On being arraigned before the Court, the recidivist can be sent to an Assessment Centre for two months where a detailed and comprehensive assessment by a multidisciplinary team takes place. As a result of the assessment a degree of mental responsibility is estimated, though how this is achieved is not demonstrated. When before the Court, the prisoner can be sentenced to prison plus TBR, or TBR.

The facilities and staffing ratios shown are far better than for equivalent treatment facilities in England. There seem to be few complaints procedures such as we have in England, e.g. Mental Health Act Commission visitors.

This is a well produced film but with a negative slant. It lasts 85 minutes and is somewhat overlong. The camera work is good. The English sub-titles are at times difficult to follow. For an English audience some introductory facts about the Dutch law of TBR would be helpful. It demonstrates the difficulties of psychiatric treatment in maximum secure conditions, for in many ways, the two philosophies are antipathetic. The film could make a good focus for discussion for both professional and lay groups.

Sponsors: KRO Broadcasting Corp., Netherland's Department of Justice, Queen Juliana Foundation. Producer: Olivier Koning, Red Dog Productions, Amsterdam. Format: VHS. Distributors: Netherlands Information Service, PO Box 20006, 2500EA The Hague, Netherlands.

Balderton Hospital

H. HUNTER

Newark, Notts

C. J. Jung: Professor C. A. Meier in Conversation with Dr N. D. Minton (UK, 1985, 80 mins)

Dr N. D. Minton, Consultant Psychiatrist and tutor at St Peter's Hospital, Surrey, has collaborated with the University of London Audio-Visual Centre and the University of Zurich to produce two forty-minute video-cassettes of an interview with Professor C. A. Meier, the distinguished Swiss psychiatrist, and one of the few remaining of Jung's close professional associates.

In the first part, Minton and Meier discuss sympathetically Jung's work and ideas, particularly during the 1930s; the Freud-Jung relationship; the association experiment; and the complex. In the second instalment, they discuss the therapeutic importance of dreaming, and some of Professor Meier's ideas on psychosomatic medicine.

The interview, which assumes some familiarity with Jung's work, is available on VHS $(£ 40.00)$ or U-matic (£50.00) from the Administrator, University of London, Audio-Visual Centre, North Wing Studios, Senate House, London, WCIE 7JZ (telephone: 01-636 8000). However, free loan can be arranged for bodies affiliated to the University of London.

Institute of Psychiatry

GREG WILKINSON

London SE5

Catalogue 1985-87 (Concord Films Council)

The 1985-87 Catalogue is now available from the Concord Films Council, 201 Felixstowe Road, Ipswich, Suffolk IP3 9BJ, at $£ 2.50$ (post free) plus $£ 1.0$ for all supplements up to 1987.

Listing well over 4,000 films, the majority of which are also available as videotapes (sale or hire), this represents remarkable value. Concord is one of the largest distributors in the UK and concentrates on programmes of social concern; there are over $\mathbf{2 0 0}$ titles of direct relevance to mental disorder and many others that could be used in psychiatry for discussion purposes. An essential reference for anyone with an interest in the audio-visual media.

TLP 